\title{
Seawater stable strontium isotope fluctuations over glacial/interglacial cycles
}

\author{
MADISON WOOD ${ }^{1}$, ANA KOLEVICA ${ }^{2}$, ANTON \\ EISENHAUER $^{3}$, MATHIS HAIN ${ }^{1}$, ANDY RIDGEWELL ${ }^{4}$, \\ ELIZABETH M. GRIFFITH ${ }^{5}$ AND ADINA PAYTAN ${ }^{6}$ \\ ${ }^{1}$ University of California - Santa Cruz \\ ${ }^{2}$ Helmholtz Centre for Ocean Research Kiel, GEOMAR \\ ${ }^{3}$ GEOMAR Helmholtz Centre for Ocean Research Kiel \\ ${ }^{4}$ University of California - Riverside \\ ${ }^{5}$ The Ohio State University \\ ${ }^{6}$ University of California, Santa Cruz \\ Presenting Author: mamwood@ucsc.edu
}

The stable strontium ( $\mathrm{Sr}$ ) isotopic composition $\left(\delta^{88 / 86} \mathrm{Sr}\right)$ of seawater has recently been shown to have fluctuated systematically over the past 35 million years, indicating a dynamic ocean $\mathrm{Sr}$ budget [1]. The data also revealed that Holocene core-top barites have higher $\delta^{88 / 86} \mathrm{Sr}$ than the average value of samples representing the past $\sim 2.5 \mathrm{Myr}$, providing support for the hypothesis that the modern ocean $\mathrm{Sr}$ budget is in disequilibrium due to increased post-glacial weathering and/or increased carbonate deposition on continetal shelves during high stand sea level [1-4]. We hypothesize that transient changes in the ocean $\mathrm{Sr}$ inventory and seawater $\delta^{88 / 86} \mathrm{Sr}$ occurred over glacial/interglacial cycles primarily in response to shifting carbonate burial between neritic (primarily Sr-rich aragonite) and pelagic (primarily Sr-poor calcite) environments. During high sea level stands, increased precipitation of aragonite on continental shelves would decrease the ocean $\mathrm{Sr}$ inventory while increasing seawater $\delta^{88 / 86} \mathrm{Sr}$ since carbonate preferentially incorporates light $\operatorname{Sr}\left(\Delta_{\text {carb-sw }}=-0.18 \%\right)$. During glacial periods, weathering and recrystalization of exposed shelf carbonates would add isotopically light $\mathrm{Sr}$ to the ocean.

To test this hypothesis, we measured $\delta^{88 / 86} \mathrm{Sr}$ and radiogenic $\mathrm{Sr}$ $\left({ }^{87} \mathrm{Sr} /{ }^{86} \mathrm{Sr}\right)$ in marine barite, a mineral that forms in the water column and records both seawater ${ }^{87} \mathrm{Sr} /{ }^{86} \mathrm{Sr}$ and $\delta^{88 / 86} \mathrm{Sr}$ (with a constant offset of $0.53 \%$ ) $[1,5]$. Box model scenarios which test the response of the ocean $\mathrm{Sr}$ budget to variable glacial/interglacial weathering-recrystalization fluxes and partitioning of carbonate burial between continental shelves and the deep ocean indicate that significant fluctuations in the $\mathrm{Sr}$ inventory could occur. Preliminary results from the past $0.5 \mathrm{Myr}$ show considerable variability consistent with model results.

[1] Paytan et al. (in press), Science. [2] Krabbenhöft et al. (2010), Geochimica et Cosmochimica Acta 74, 4097-4109. [3] Pearce et al. (2015), Geochimica et Cosmochimica Acta 157, 125-146. [4] Vance et al. (2009), Nature 366, 445-449. [5] Paytan et al. (1993), Nature 458, 493-496. 